\title{
Evaluation of coding-independent functions of the transcribed bovine aromatase pseudogene CYP19P1
}

\author{
Marina Chwalisz and Rainer Fürbass ${ }^{*}$
}

\begin{abstract}
Background: CYP19A1 encodes the aromatase which catalyzes the final reaction of estrogen biosynthesis. The bovine genome also contains a non-coding copy of CYP19A1, the transcribed pseudogene CYP19P1. Whereas CYP19A1 is transcribed in all estrogen-producing tissues, mainly in the placenta and gonads, the CYP19P1 transcript so far was detected in the placenta. Strikingly, one sequence segment of both transcripts exhibits an exceptional high identity of 98\%, which implies selective pressure and suggests some kind of function. Only recently, indeed, coding-independent functions of several transcribed pseudogenes were reported. Therefore, we analyzed CYP19P1 and CYP19A1 transcripts with the aim to detect clues for gene-pseudogene interference.
\end{abstract}

Findings: The CYP19P1 transcript was first examined in silico for the presence of microRNA coding sequences and microRNA targets. Further, to identify tissues where CYP19P1 and CYP19A1 transcripts are co-expressed, as a pre-requisite for transcript interference, expression profiling was performed in a variety of bovine tissues. Our in silico analyses did neither reveal potential microRNA coding sequences, nor microRNA targets. Co-expression of the CYP19 loci was demonstrated in placental cotyledons and granulosa cells of dominant follicles. However, in granulosa cells of dominant follicles the concentration of CYP19P1 mRNA was very low compared to CYP19A1 mRNA.

Conclusions: CYP19P1 and CYP19A1 transcripts might interfere in placental cotyledons. However, in granulosa cells of dominant follicles relevant interference between gene and pseudogene transcripts is unlikely to occur because of the very low CYP19P1/CYP19A1 transcript ratio.

Keywords: CYP19A1, Placenta, Granulosa, Gene-pseudogene interference

\section{Findings \\ Background}

CYP19A1 encodes the aromatase which catalyzes the conversion of androgens to estrogens. During an earlier screening of a bovine placental cDNA library for CYP19A1 clones, we also isolated cDNA clones of a homologous pseudogene, CYP19P1 [1,2]. Gene and pseudogene transcripts exhibit major differences due to the loss of several exons in the CYP19P1 transcript. Furthermore, numerous mutations in the pseudogene sequence produced multiple translational stop codons in all reading frames and thereby abrogated its protein-coding function. Strikingly, however, mutations are unevenly distributed. A sequence segment

\footnotetext{
* Correspondence: fuerbass@fbn-dummerstorf.de

Leibniz Institute for Farm Animal Biology (FBN), Wilhelm-Stahl-Allee 2, Dummerstorf 18196, Germany
}

of 177 bp corresponding to exon 5 of CYP19A1 is highly conserved, showing $98 \%$ identity, compared to $89 \%$ sequence identity in general [2]. Both CYP19 loci are located on the same strand of chromosome 10, being separated by $20 \mathrm{~kb}$ of genomic DNA $[3,4]$.

Pseudogenes for long were considered as defunct copies of functional genes. However, recent evidence suggests that some pseudogenes might exert coding-independent functions [5,6]. Interestingly, gene-pseudogene interference was demonstrated by selective knock-down of the $A B C C 6 P 1$ pseudogene, which led to a decreased transcription of its $A B C C 6$ parent gene [7]. This recent evidence prompted us to take up again our analysis of the CYP19P1 pseudogene with the aim to detect clues of gene-pseudogene interference. To this end, transcripts were searched in silico for microRNA-coding sequences and microRNA targets. Further, expression profiles of 
CYP19A1 and CYP19P1 were analyzed in a variety of bovine tissues.

\section{Materials and methods}

Samples from placentas, ovarian granulosa cells, fetal ovaries, endometria, adrenal glands and livers were collected from slaughtered cows in a local abattoir. Tissue samples were stored in RNAlater (Qiagen, Hilden, Germany) at $-20^{\circ} \mathrm{C}$. Granulosa cells were frozen in liquid nitrogen and stored at $-80^{\circ} \mathrm{C}$. Placental cotyledons and caruncles were separated manually. Despite careful separation, caruncle samples might contain traces of cotyledonary cells. Ovarian dominant and pre-ovulatory follicles collected before and after the LH-surge, respectively, were identified as described in [8]. Follicles were punctured with $18 \mathrm{G}$ needles and granulosa cells were aspirated. Total RNA was prepared using the NucleoSpin RNA II Kit (Macherey-Nagel, Düren, Germany), according to the supplier's protocol. This procedure included oncolumn DNaseI digestion to remove traces of DNA. RNA was quantified in a NanoDrop 1000 spectrophotometer (PeQLab, Erlangen, Germany). RNA integrity was confirmed by denaturing agarose gel electrophoresis.

The abundance of CYP19P1 and CYP19A1 transcripts was measured by quantitative reverse transcription PCR (qPCR). For normalization purposes, the RPLPO transcript encoding a ribosomal large subunit protein was also measured. RNA (100 ng) was reverse transcribed in a $25 \mu \mathrm{l}$ reaction volume using a mixture of random hexameric and oligo dT primers (Roche, Mannheim, Germany) and M-MLV reverse transcriptase (Promega, Mannheim, Germany). cDNA was purified with the High Pure PCR Product Purification Kit (Roche). For subsequent real time PCR, cDNA was amplified in a $12 \mu \mathrm{l}$ reaction volume with the SensiFast SYBR No-ROX Kit (Bioline, Luckenwalde, Germany) using following primer pairs:

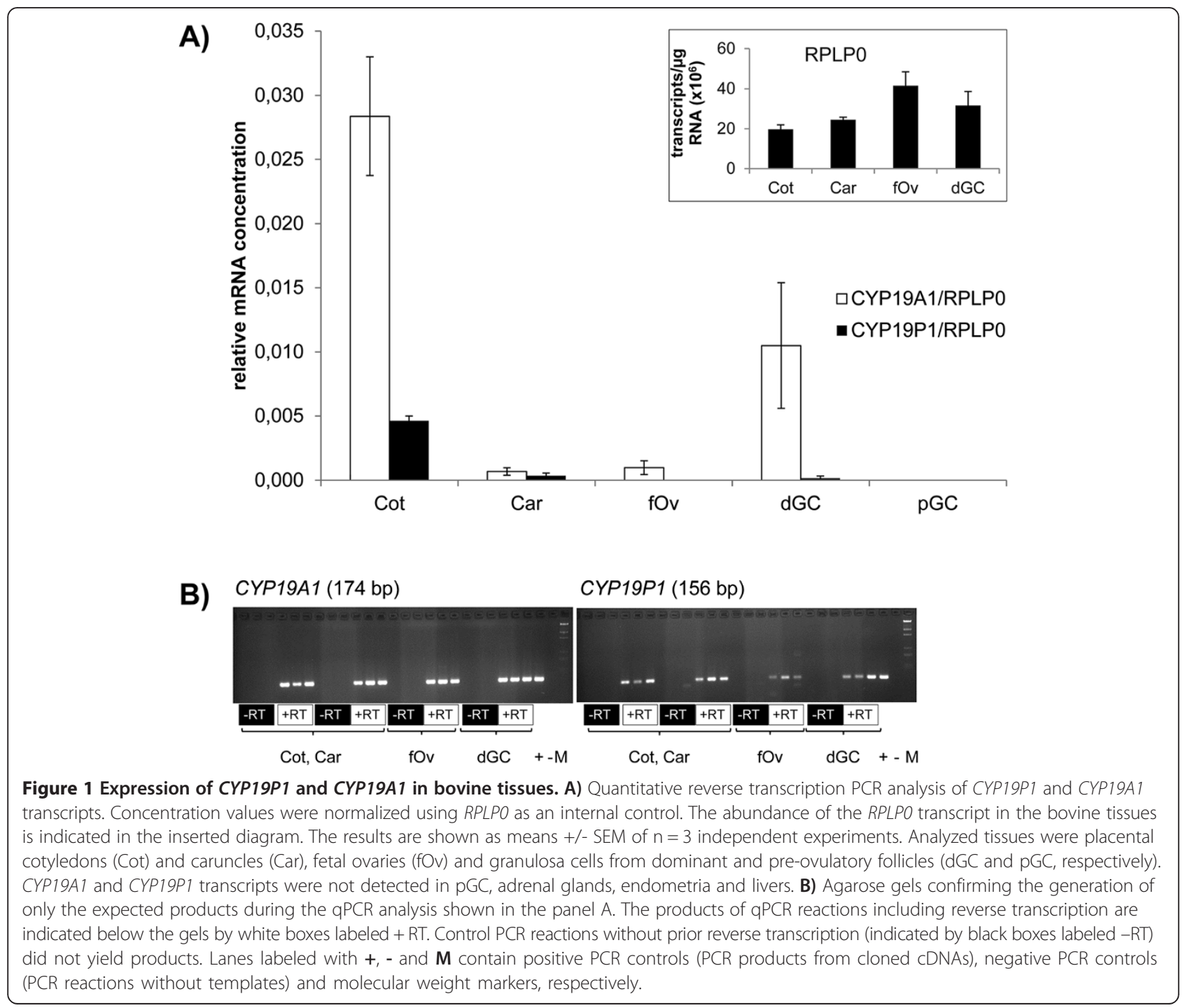


CYP19P1_for, 5'-TCATTACAACGCATCCCCAGGTT GA-3'/CYP19P1_rev, 5'-CTAGGTCCATGACGGGCT

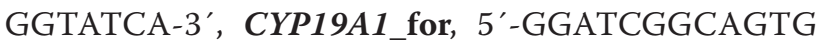
CCTGCAATTACTA-3'/CYP19A1_rev, 5'-ATGCCGA TGAACTGCAACCCAAGTT-3' and RPLP0_for, 5' TGGTTACCCAACCGTCGCATCTGTA-3'/RPLP0_rev, 5'-CACAAAGGCAGATGGATCAGCCAAG-3' (SigmaAldrich, Taufkirchen, Germany). The primer pairs were designed to flank intronic sequences of genomic DNA. The expected products from cDNA were 156, 174 and $140 \mathrm{bp}$ in length, respectively. The amplification and quantification of resulting PCR products were performed in a Light-Cycler 480 instrument (Roche) under following cycling conditions: Pre-incubation at $95^{\circ} \mathrm{C}$ for $5 \mathrm{~min}$, followed by 40 cycles of denaturation at $95^{\circ} \mathrm{C}$ for $20 \mathrm{~s}$, annealing at $60^{\circ} \mathrm{C}$ for $15 \mathrm{~s}$, and extension at $72^{\circ} \mathrm{C}$ for
$15 \mathrm{~s}$, and single point fluorescence acquisition at $75^{\circ} \mathrm{C}$ for $10 \mathrm{~s}$ to avoid quantifying primer artifacts. The generation of only the expected products was confirmed by melting curve analysis and agarose gel electrophoresis, which did not reveal PCR products from genomic DNA (Figure 1B). External standard curves were generated by co-amplification of various dilutions of cloned PCR products $\left(5 \times 10^{-12}\right.$ to $5 \times 10^{-16} \mathrm{~g} \mathrm{DNA} /$ reaction) with the corresponding primer pairs.

The statistical analyses were performed with the Sigma Plot 12.0 Analysis System (Jandel Scientific, San Raffael, CA, USA).

\section{Results and discussion}

The remarkably high conservation of CYP19P1 in the exon 5-homologous sequence segment (henceforth referred to

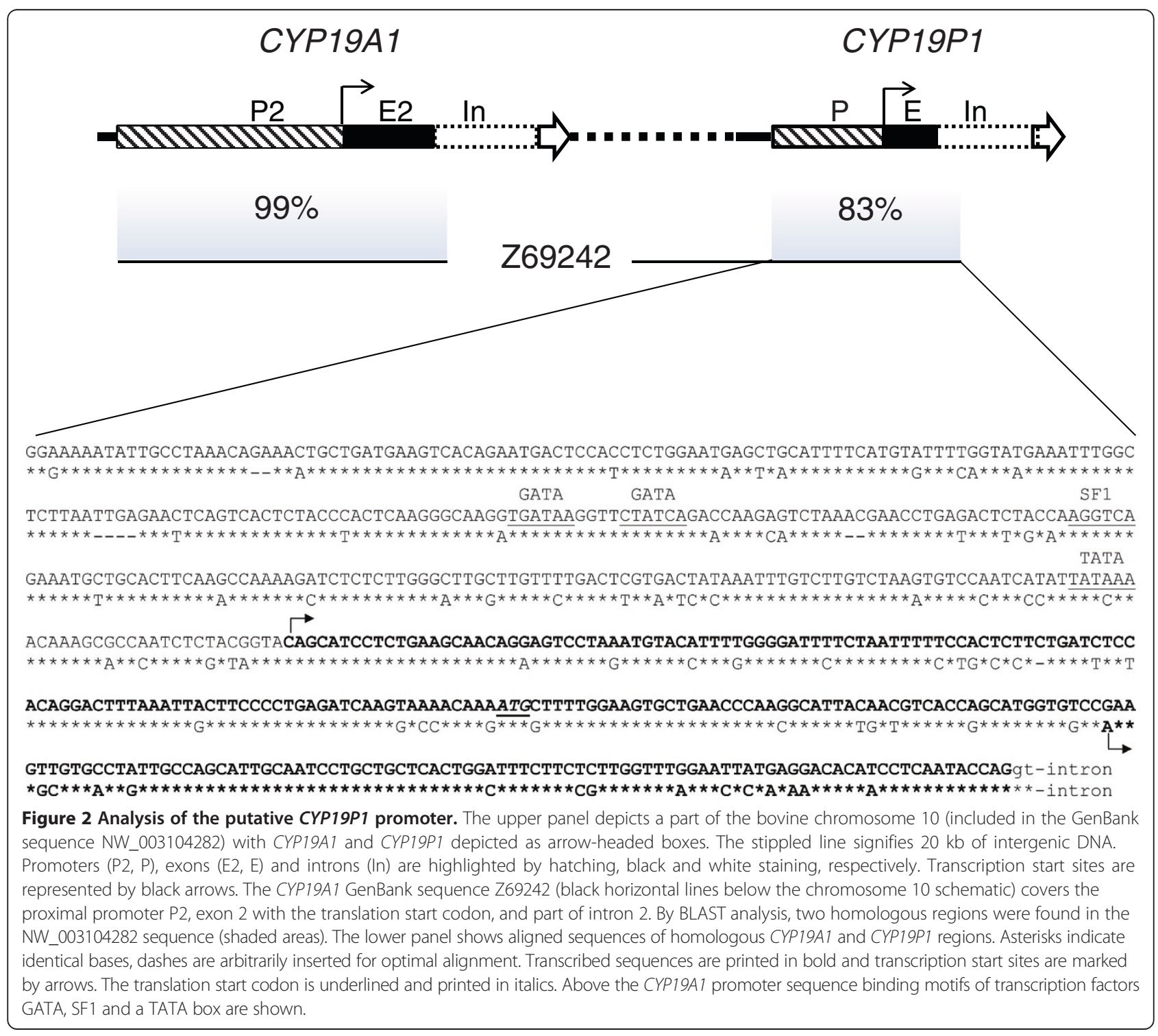


as P1-exon 5) implies selective pressure. Hence, it might well be that the pseudogene exerts a coding-independent biological activity via the P1-exon 5 . Because pseudogenederived small interfering RNAs were shown to regulate gene expression in mouse oocytes [9], we examined if also the CYP19P1 transcript encodes microRNAs. We performed in silico analyses of the P1-exon 5 using the free software RNAfold [10] to detect putative stable premicroRNA hairpins. However, no such structures were predicted by the program. The cellular abundance of the tumor suppressor gene PTEN transcript was found to be regulated by the transcript of the highly homologous PTENP1 pseudogene via competition for microRNA binding [11]. To evaluate if the CYP19 gene pair could also interfere this way, we searched the P1-exon 5 for microRNA target sites using the MIRANDA software [12]. However, probable targets of known microRNAs were not found. Other pseudogenes are transcribed in an antisense orientation and lead to silencing of their parent genes by translational interference [5]. However, this mode of action can not apply to CYP19P1 and CYP19A1 which are both encoded by the same strand of chromosome 10 [4] and hence are transcribed in the same orientation.

For possible interference, CYP19P1 and CYP19A1 transcripts need to be co-expressed. So far, expression of CYP19P1 has not been studied in bovine tissues other than placenta. To evaluate co-expression as a prerequisite for transcript interference, we performed qPCR to measure the abundance of CYP19P1 and CYP19A1 transcripts in a variety of bovine tissues. These included granulosa cells from dominant follicles and placental cotyledons, which were known to express CYP19A1 [13]. Further, granulosa cells from pre-ovulatory follicles, fetal ovaries, placental caruncles, endometrium, adrenal gland and liver were also analyzed, to find out whether the tissue-specificity of CYP19A1 expression is retained in CYP19P1. The results of the qPCR experiments are presented in Figure 1A. As expected, cotyledons and granulosa cells from dominant follicles expressed considerable amounts of the CYP19A1 transcript. In contrast, the CYP19A1 transcript concentration was low or undetectable in the remaining tissue samples. Likewise, the CYP19P1 transcript was found in cotyledons and granulosa cells from dominant follicles, however, at a very low concentration. The ratio CYP19P1/ CYP19A1 of mean transcript concentrations was 0.16 and 0.016, respectively. Considering these results CYP19P1 and CYP19A1 transcripts might interfere in placental cotyledons, although the underlying mechanism remains unclear. On the other hand it is unlikely that the CYP19P1 transcript plays a major role in the regulation of CYP19A1 expression in granulosa cells of dominant follicles. Interestingly, however, in granulosa cells from pre-ovulatory follicles CYP19P1 expression is shut down, just as known from CYP19A1, as a consequence of the pre-ovulatory
LH-surge $[14,8]$. The apparent congruent tissue-specificity of CYP19 gene and pseudogene could be explained by promoter conservation. A genomic DNA sequence covering the entire CYP19A1 and CYP19P1 loci is present in the database [GenBank:NW_003104282]. We defined the genomic sequence immediately upstream of the transcribed CYP19P1 sequence as potential pseudogene promoter and compared it with promoters of CYP19A1 by BLAST analysis. Thereby we found, that $483 \mathrm{bp}$ of the proximal CYP19A1 promoter 2 ([15]; [GenBank:Z69242]) were duplicated during pseudogene genesis (Figure 2). We have verified the sequence by sequencing cloned PCR products (data not shown). Gene and pseudogene promoters exhibit $83 \%$ sequence identity. Although binding motifs of GATA and SF1 transcription factors are retained, the putative pseudogene promoter has lost the functional TATA box, which might explain the low promoter activity and the use of an alternative transcription start site.

\section{Competing interests}

The authors declare that they have no competing interests.

\section{Authors' contributions}

MC implementation, analysis of data and preparation of the manuscript. RF initiation of the study, analysis of data, preparation of the manuscript. Both authors read and approved the final manuscript.

\section{Acknowledgements}

We thank Dr. R. M. Brunner and F. Hadlich for providing assistance with in silico analyses, Maren Anders and Veronica Schreiter for excellent technical assistance. This work was supported by a grant from the Deutsche Forschungsgemeinschaft (DFG).

Received: 30 September 2013 Accepted: 13 June 2014

Published: 20 June 2014

\section{References}

1. Vanselow J, Fürbass R: Novel aromatase transcripts from bovine placenta contain repeated sequence motifs. Gene 1995, 154:281-286.

2. Fürbass $\mathrm{R}$, Vanselow J: An aromatase pseudogene is transcribed in the bovine placenta. Gene 1995, 154:287-292.

3. Goldammer T, Guérin G, Brunner RM, Vanselow J, Fürbass R, Schwerin M: Chromosomal mapping of the bovine aromatase gene (CYP19) and an aromatase pseudogene to chromosome 10 and syntenic group U5. Mam Genome 1994, 5:822-823.

4. Brunner RM, Goldammer T, Fürbass R, Vanselow J, Schwerin M: Genomic organization of the bovine aromatase encoding gene and a homologous pseudogene as revealed by DNA fiber FISH. Cytogenet Cell Genet 1998, 82:37-40.

5. Pink R, Wicks K, Caley D, Punch E, Jacobs L, Carter D: Pseudogenes: pseudo-functional or key regulators in health and disease? RNA 2011, 17:792-798

6. Pei B, Sisu C, Frankish A, Howald C, Habegger L, Mu X, Harte R, Balasubramanian S, Tanzer A, Diekhans M, Reymond A, Hubbard T, Harrow J, Gerstein M: The GENCODE pseudogene resource. Genome Biol 2012, 13:R51.

7. Piehler AP, Hellum M, Wenzel J, Kaminski E, Haug K, Kierulf P, Kaminski W: The human $A B C$ transporter pseudogene family: evidence for transcription and gene-pseudogene interference. BMC Genomics 2008, 9:165.

8. Nimz M, Spitschak M, Schneider F, Fürbass R, Vanselow J: Down-regulation of genes encoding steroidogenic enzymes and hormone receptors in late preovulatory follicles of the cow coincides with an accumulation of intrafollicular steroids. Domest Anim Endocrinol 2009, 37:45-54.

9. Tam O, Aravin A, Stein P, Girard A, Murchison E, Cheloufi S, Hodges E, Anger M, Sachidanandam R, Schultz R, Hannon G: Pseudogene-derived small interfering RNAs regulate gene expression in mouse oocytes. Nature 2008, 453:534-539. 
10. Gruber A, Lorenz R, Bernhard S, Neuböck R, Hofacker I: The Vienna RNA websuite. Nucleic Acids Res 2008, 36:W70-W74.

11. Poliseno L, Salmena L, Zhang J, Carver B, Haveman W, Pandolfi P: A coding-independent function of gene and pseudogene mRNAs regulates tumor biology. Nature 2010, 465:1033-1040.

12. Enright A, John B, Gaul U, Tuschl T, Sander C, Marks D: MicroRNA targets in Drosophila. Genome Biol 2003, 5:R1.

13. Vanselow J, Fürbass R, Rehbock F, Klautschek G, Schwerin M: Cattle and sheep use different promoters to direct the expression of aromatase cytochrome P450 encoding gene, Cyp 19, during pregnancy. Domest Anim Endocrinol 2004, 27:99-114.

14. Voss AK, Fortune JE: Levels of messenger ribonucleic acid for cytochrome P450 17alpha-hydroxylase and P450 aromatase in preovulatory bovine follicles decrease after the luteinizing hormone surge. Endocrinology 1993, 132:2239-2245.

15. Fürbass R, Kalbe C, Vanselow J: Tissue-specific expression of the bovine aromatase encoding gene uses multiple transcriptional start sites and alternative first exons. Endocrinology 1997, 138:2813-2819.

doi:10.1186/1756-0500-7-378

Cite this article as: Chwalisz and Fürbass: Evaluation of

coding-independent functions of the transcribed bovine aromatase pseudogene CYP19P1. BMC Research Notes 2014 7:378.

\section{Submit your next manuscript to BioMed Central and take full advantage of:}

- Convenient online submission

- Thorough peer review

- No space constraints or color figure charges

- Immediate publication on acceptance

- Inclusion in PubMed, CAS, Scopus and Google Scholar

- Research which is freely available for redistribution 